Indeed the only Western mystic we find is that Viennese engineer who was "indifferent to the solution of scientific problems". I hope that the propeller Richard Gregory reports him as designing actually worked.

But the very worst I have left 'til last: the Companion has entries (some of them quite long) under astrology, extra-sensory perception, ghost, levitation, paranormal (this, that and the other), spiritualism and telekinesis. I do realize that many people are keen on such things, but I see no good reason why that attitude should be pampered. Just as the first responsibility of a hospital is to not spread disease, so the first responsibility of a Companion to the Mind is to not encourage superstition. There are plenty of problems awaiting solution before we need concern ourselves overmuch with mysteries. I would happily have swapped all these para-chapters for an extended essay by that truly great student of matter-over-mind, James ("The Amazing") Randi.

John C. Marshall is in the Neuropsychology Unit, part of the Neuroscience Group at the Radcliffe Infirmary, Oxford $O X 26 \mathrm{HE}, U K$

\section{On speaking terms}

\section{J.Z. Young}

Mindwaves: Thoughts on Intelligence, Identity and Consciousness. Edited by Colin Blakemore and Susan Greenfield. Basil Blackwell: 1987. Pp. 525. £19.50, $\$ 24.95$.

RECENT discoveries in neuroscience have introduced new controversies into the problem of how best to speak of the relations between mind and brain. This book provides 32 opinions on the subject and makes a fascinating study of the different approaches of philosophers and scientists. Neuroscientists feel that they have been helped by adopting part of the terminology of communication engineering and computer science, but some philosophers claim that the use of such terms introduces dangerous conceptual confusions into the debate.

The philosopher Peter Hacker and linguist Roy Harris have taken their task to be correction of the mythological language used by physiologists, picking on Frisby, Barlow, Phillips, Zeki and especially as expressed in my own book Programs of the Brain. They object to such terms as 'information', 'coding', 'language', 'mapping' or 'representation' being used in genetics and neuroscience. saying that they are misapplied and may lead to "disastrous equivocations" or misleading metaphors that cannot be tested.

All discussion is helpful but these criticisms show surprisingly little sense of history and are short-sighted and obscurantist. They miss the point that all living things are agents and communication systems. Biology advances in line with technology, applying to human beings and animals the understanding and terminology derived from prosthetic devices that replace or augment our functions. These terms from communication engineering are part of current language. Geneticists, biochemists and neuroscientists find it useful to speak of communication of information by codes and the setting up of representations: most of the contributors to this volume use such words and they are not likely to stop doing so because philosophers insist that these terms should be used only in restricted senses and about whole human persons.

It is worthwhile examining this problem further. The ability to communicate by conventional code signs is characteristic of living things. It provides the information that maintains the pattern of order that allows life to delay the increase of entropy. Signals that transmit this semantic information are indeed parts of the pre-arranged communication systems of genes, hormones and brains. To quote Hacker himself: "A symbolic description is presumably an array of symbols which are so combined as to yield a true (or false) characterisation of a certain aspect of the world. It must be cast in a certain language which has a vocabulary and a grammar". Living things can be said to use symbols in just this way and the points of view of these philosophers obscure this fundamental fact about life. Moreover, the critics imply an unacceptable dualism: they seem not to realize the axiom of psycho-physical intimacy; you and your brain are inseparable, why separate them linguistically? Hacker says that "it makes no sense to speak of the brain containing knowledge or information written in its own language". On the contrary, neuroscientists are beginning to give good sense to that statement. Jeffrey Gray has no doubts: "all human languages are stuffed full of rules. . . . The rules, then, must be contained in the heads of those speakers and hearers".

The linguist Harris might ask "Which rules?", because grammars are embarrassingly numerous. How do you hope to find them in the brain when linguists do not know what they are? One must agree that scientists when speaking of a 'language' do not consider all the subtle problems that have arisen since de Saussure discussed the difference between 'langage' and 'langue'. There are difficulties in the use of such terms as 'information', 'coding' and 'representation' and we try to define them in general biological terms, as I have done more recently in my book Philosophy and the Brain. It is unsurprising that such changes of use upset those who do not look at the whole living world, but it is disappointing that the critics show so little understanding when one hoped for help with common problems.

Surely a wider view will help with the classic problem of the mental and the physical. Harris believes that neuroscientists "do not wish to be restricted by accepting the traditional distinction between 'brain' and 'mind'" and he claims that the motivation of the biologist is that he "wants to be in on the act when it comes to solving these ultimate scientific mysteries: how do human beings think? and what is thought?". This is an unworthy tone for one scholar to adopt of others who are working in an obviously related subject. Most neuroscientists do indeed feel that a re-consideration is necessary. In a wise article, Paul Seabright discusses the "tensions that arise between the mind we experience and as explained by science". For one thing "the physical world is everywhere; it has no pockets into which non-physical objects could fit.

But most of us also think many things that exist are not just physical objects". So how are we to describe this property of mentality that attaches to ourselves and perhaps at least to some animals?

The first essential is not to separate the aspects too widely. Stephen Clark echoes Seabright on this: "a surprising number of people still seem to think that offering an explanation in terms of intention and feelings or the like is somehow incompatible with an explanation in terms of physiological conditions, as if intention occupied space to the exclusion of nerve fibres". Ted Honderich presses the point that "Neuroscience... must change the philosophy of mind . . mainly because it establishes the axiom or proposition of psycho-physical imtimacy". He goes on with his suggestion of how we should formalize this co-occurrence: "Consciousness, truly described by the metaphor of the interdependent subject and object, does exist". He characterizes their relationship as one of nomic (law-like) connection. Nicholas Humphrey uses a different metaphor: "consciousness is in fact a picture of the workings of the brain".

Euan Macphail, a psychologist, asks "When we solve problem $\mathrm{X}$, what processes are taking place in our minds (or brains)?". This has the unfortunate effect of suggesting that the mind is somehow an entity that can contain processes. Surely, as Ayer has said, "We do not need to conceive of minds as substances, or indeed as entities of any kind". It is better to say with Colin McGinn, "Still, the brain is a physical entity and it is conscious, so it must have some design feature, presumably 'physical' in nature (whatever that might mean), that makes it conscious". But, he continues, "we do not at present know what that feature is, and so we do 
not at present know how to build a machine which matches this achievement of the brains".

John Searle's explanation of the 'causal' relationship between mental states and the brain is "The existence of two causally real levels of description in the brain, one a macro-level of mental neurophysiological processes and the other a micro-level of neuronal physiological processes exactly analogous to the existence of two causally real levels of description of a hammer". One wonders whether the words "exactly analogous" suffice to solve this ancient question?

Jack Eccles provides his frankly dualistic solution with the concept of mentalneural event neurons (MNE) sitting at higher levels above mere neural event neurons (NE): "In special circumstances their [MNE] firing would be in unison (identity) with mental events". Searching for the means of such mental-neural interaction, Eccles calls upon the possibility suggested by Margenau that the mind operates as a "probability field of quantum mechanics". However Seabright points out that quantum laws are random and so cannot be the basis of psychological law or intention, a view that is held also by Honderich. Roger Penrose too considers that "the introduction of quantum mechanics [makes] no essential difference", but he raises the interesting suggestion that "there is something very incomplete about quantum theory as it stands".

Rodolfo Llinás makes a determined effort to show how "sensory inputs [are placed] 'into internal context' . . . so that these inputs may be understood by the nervous system". His account involves "organised patterns of electrical activity in neurons, which may be described and formally treated as implementing a

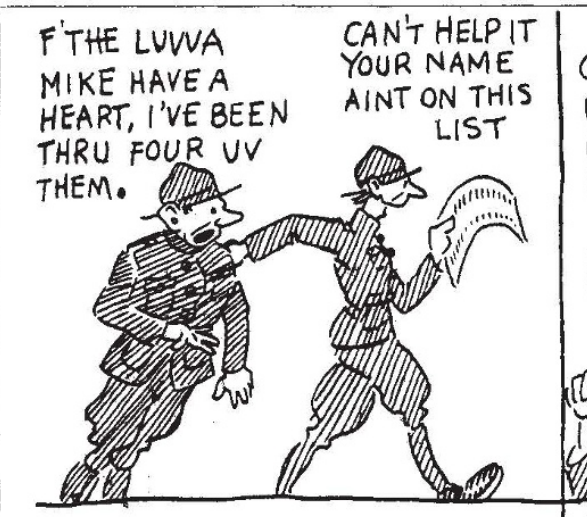

UNDERLINE TWO WOROS WTHTHE SAME MEANING, PALAEOZOIC, FOSSILIFEROUS, PERIPHRASTICALLY SZAIBELYITE, NOW I'M NOT TOO SURE ABOUT THOSE TWO?

GOSH!
WHAT
KIND
UV
WAR
ISTHIS
ANYWAYS

ON THE FIRST PAGE NOTICE A SQUARE WITHIN THAT SQUARE IS A TRIANGLE AND IN THE SQUARE AND TRIANGLE IS A CIRCLE, IN THE CIRCLE NOT IN THE SQUARE BUT IN THE TRIANGLE PUT THE FIGURE FOUR BILLION AND NOTHINE. DO NOT WRITE UNTIL I SAY GO, WHEN

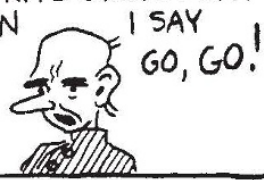

\section{LET'S SEE HERE'S ONE}

THAT'S GOT ME STUMPED, A ZULU HASHOW MANY LEGS? EPIGASTRIUM SHOULD, ESOPHAGUS IS WHAT, I'LL HAVE TO GUESS AT THAT ONE!

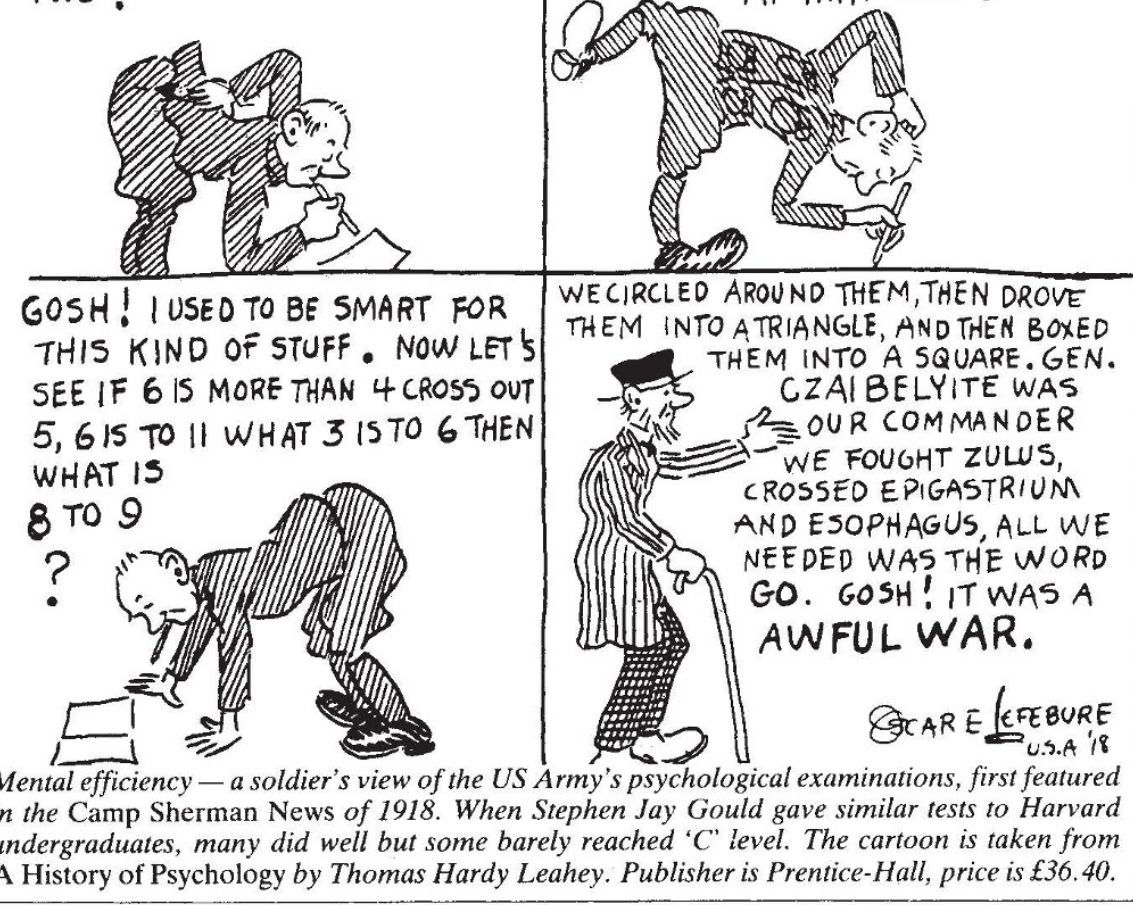

functional space". He ends by hoping that "Ultimately understanding of the mind may not be as intricate as our vanity hoped or our intellect feared".

Other authors discuss the possible functions of mentality and consciousness, and several of them are ready to ascribe these properties to animals. Nick Mackintosh provides evidence that even "rats and pigeons in boring experiments on conditioning" show evidence of knowledge of and belief about the world, but he warns that "this is not necessarily an appropriate language for scientific analysis". Herbert Terrace argues that in apes we have evidence of animal thought but not the characteristics of human language. Further, "recent experiments on animal memory provide compelling support for the idea that animals do form representations". Evidence for internal representation in fishes is also provided by Macphail from studies of their electrical emissions.

Thus the contributors to this book do not seem to wish to dismiss mental events; but they do try to clarify their relations with brain events. Many of them write of the brain as using a language of symbols and setting up maps and representations. It is difficult to see that this is leading them to the confusion over the working or nature of the brain which Hacker and Harris fear. Of course, these words are not used in exactly the same sense when applied to brains and human language. But because all mentality is closely correlated with brain activity, it is unlikely that wholly different terminology is needed for the two. Perret, Rolls and Caan have shown that there are cells in the cortex of a monkey that are selectively responsive when the face of a monkey or human is shown. Surely the presence of these cells in monkeys, and no doubt in man, contradicts Hacker's claim that "nothing in the cortex constitutes a "symbolic representation' of the creature's environment".

We need techniques to study how such gnostic cells interact with others to provide the action system that allows a monkey or a man to have mental and physical reactions appropriate to friend or foe. Such an enquiry involves considering the whole brain as an agent, which is a holistic approach that is not easy for physiologists. Objections to the use of the metaphors under discussion can actually delay discovery by forcing investigators back to the use of simple physical principles only. So I hope that neuroscientists will not be put off by philosophical sophistries. We need to pay more attention to human and linguistic models, not less, in order to help with the task of understanding mentality and the brain.

J.Z. Young, Department of Experimental Psychology, University of Oxford, South Parks Road, Oxford $O X I$ 3UD, UK, is Emeritus Professor of Anatomy in University College London. 